\title{
Parametric Model Based Approach for Consumer Load Prediction
}

\author{
Ayodele Isqeel Abdullateef ${ }^{1^{*}}$, Mudathir Folohunso Akorede ${ }^{1}$, Abubakar Abdulkarim ${ }^{2}$ and Momoh-Jimoh \\ Eyiomika Salami ${ }^{3}$
}

\author{
${ }^{1}$ Department of Electrical and Electronics Engineering, University of Ilorin, Nigeria. \\ ${ }^{2}$ Department of Electrical Engineering, Ahmadu Bello University Zaria, Nigeria. \\ ${ }^{3}$ Department of Electrical and Electronics Engineering, Elizade University Ilara Mokin, Nigeria.
}

"Corresponding author: abd_lateef.aii@unilorin.edu.ng, Tel: +2348086215103

\begin{abstract}
Various load prediction techniques have been proposed to predict consumer load which represents the activities of the consumer on the distribution network. Usually, these techniques use cumulative energy consumption data of the consumers connected to the power network to predict consumer load. However, these data fail to reveal and monitor the activities of individual consumer represented by the consumer load consumption pattern. A new approach of predicting individual consumer load based on autoregressive moving average model (ARMA) is proposed in this study. Sub- optimal technique of parameter estimation based on Prony method was used to determine the model order of the ARMA models ARMA $(10,8)$, ARMA $(8,6)$ and ARMA $(6,4)$. ARMA $(6,4)$ was found to be appropriate for consumer load prediction with an average mean square error of 0.00006986 and 0.0000685 for weekday and weekend loads respectively. The energy consumption data acquired from consumer load prototype for one week, with 288 data points per day used in our previous work, was used and 5 -minute step ahead load prediction is achieved. Furthermore, a comparison between autoregressive AR (20) and ARMA (6, 4) was carried out and ARMA $(6,4)$ was found to be appropriate for consumer load prediction. This facilitates the monitoring of individual consumer activities connected on the power network.
\end{abstract}

Keywords: Autoregressive, autoregressive moving average, consumer load prediction, power distribution network, Prony method.

C 2019 Penerbit UTM Press. All rights reserved

Article History: received 19 June 2019; accepted 31 July 2019; published 31 August 2019.

\section{INTRODUCTION}

Electric load prediction has largely been used for energy management at generation and transmission levels, aside that it facilitates the estimation of future electricity demand based on the past records and helps the utilities in decision making and operational planning [1]. It also influences the consumers' decision in the management of energy such as load shedding and control of peak loads. However, the data used for the predictions are aggregate energy consumption data of the consumers connected to the power network. This is not unconnected to the fact that the load consumption of individual consumers are stochastic and volatile, thus, making individual consumer load prediction to be difficult [2]. Moreover, aggregate data are short of revealing individual consumer energy pattern which is essential to monitoring individual consumers' activities on the distribution network.

Numerous techniques of predicting electricity load consumption by the consumer have been recently reported [3][4][5]. Statistical methods which include multiple linear regression, exponential smoothing, time series, state space, and Kalman filter have been proposed [1][6][7]. Taylor [8] evaluated methods of very short term load prediction using British electricity demand load data. Singh, et al. [9] proposed seasonal autoregressive moving average (SARMA) for home peak load and the study noted that ability to predict the stochastic activities of the consumer and routines are more significant for home load prediction. Electricity load forecasting proposed by Koprinska, et al. [10] using autocorrelation feature selection and machine learning algorithm are considered as global model that predicts the load for all days of the week and local model that predict load for each day of the week. The models were used to analyze electricity data obtained within two years from the State of New South Wales in Australia. Trudnowski, et al. [11] proposed a strategy for developing a very short-term load prediction using slow and fast Kalman estimators and an hourly forecaster load prediction for power system automatic generation control. The Kalman model parameters were determined by matching the frequency response of the estimator to load residuals.

Application of artificial intelligent paradigm such as artificial neural network (ANN), fuzzy logic (FL) and knowledge based expert systems have been proposed for load prediction [12][13][14][6]. A method of very shortterm loads forecasting using wavelet neural networks with data pre-filtering 1-h into the future in 5-min steps proposed by Guan, et al. [15] used spike filtering technique to detect spikes in load data. The method removes spikes in real-time from the data before the load is decomposed into multiple components at different frequencies, where 
separate neural networks are applied to capture the features of individual components. Yang, et al. [16] proposed fuzzy neural system (FNS) for very-short-term electric load prediction based on chaotic dynamics reconstruction technique. Hybrid model of similar day and neural network for load forecast ranging from 15 minutes to few hours was proposed by Fok and Vai [17].

Autoregressive (AR) model has been used for consumer load prediction and electricity theft identification in our earlier work [18], however, one of the setback of the AR model is in the selection of appropriate model parameters which is essential to using the model as a predictor. Besides, the estimated model order is always high. To overcome this problem autoregressive moving average (ARMA) model based on Prony's technique is proposed in this study. This will overcome higher model order selection on one hand and predict both the valley and peaks of the consumer data on the other hand. This study proposes a new approach of forecasting individual consumer load which could be employ in the monitoring of the activities of such consumer on power system network using ARMA model.

\section{METHODOLOGY}

One week data acquired from the Consumer Load Monitoring Prototype (CLMP) constructed at the Mechatronics Laboratory, International Islamic University Malaysia, for the purpose of studying the activities of consumers on power network was used in this study. The construction details and data acquisition procedure have been well-explained and presented [19]. Typical consumer loads representing a real life situation of house hold electricity consumption was connected to the CLMP and the data acquisition was carried out via LABVIEW hardware (National Instrument, USA) device linked to the PCI 6420E channel in the computer. The data acquired was logged directly into the computer and stored for further analysis

\subsection{Autoregressive Moving Average}

Time series data acquired from the CLMP is assumed to be generated from a linear filter excited by a white noise which can be expressed as

$$
y(n)=-\sum_{k=1}^{p} a_{k} y(n-k)+\sum_{k=0}^{q} b_{k} x(n-k)
$$

where $y(n)$ and $x(n)$ are the output and input signals respectively, while $a_{k} b_{k}, p$, and $q$ are the system parameters. Analysis of Equation (1) leads to three different models: autoregressive model (AR), moving average (MA) model and autoregressive moving average model (ARMA).

The transfer function of the liner system Equation (1) can be expressed as

$$
H(z)=\frac{B(z)}{A(z)}=\frac{\sum_{k=0}^{q} b_{k} z^{-k}}{1+\sum_{k=1}^{p} a_{k} z^{-k}}
$$

where $B(z)$ and $A(z)$ are linear and inverse filter respectively. Depending on the characteristic of the filter, three types of linear prediction models exist, namely autoregressive moving average (ARMA) model, autoregressive (AR) model where $B(z)=1$ and moving average (MA) model where $A(z)=1$.

Estimation of the ARMA model parameter is fundamental to its usage as a predictor. Optima techniques such as maximum likelihood method (MLM) have been used to estimate the ARMA parameters [20]. However, this method involves nonlinear equations that are difficult to solve and moreover the computational complexity of the MLM algorithms limit their practical application. Suboptimal methods are developed in order to improve the computational difficulties that are associated with MLM parameter estimation. The reduction in computational complexity is linked to the relationship between the autocorrelation function of and the coefficients of the ARMA process. One of the most popular suboptimal techniques is Prony technique. This is based on estimation of the AR parameters first by solving the modified Yule Walker equations and then uses these estimates in deriving the MA parameters.

\subsection{Prony Technique}

The error generated form linear system illustrated in Figure 1 is expressed as

$e(n)=y(n)-h(n)$

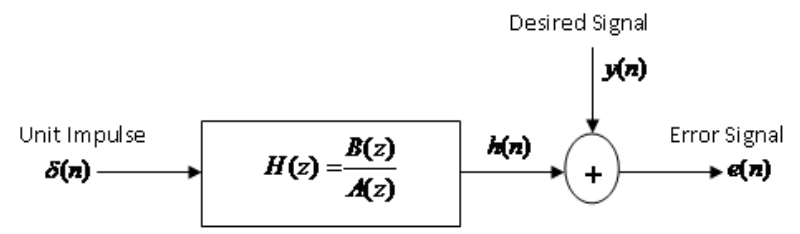

Figure 1 Linear shift-invariant system

if Equation (3) is expressed in frequency domain

$$
E^{\prime}(z)=X(z)-\frac{B_{p}(z)}{A_{p}(z)}
$$

Multiplying both sides of (4) by $A_{p}(z)$ then a new error is expressed as

$E(z)=E^{\prime}(z) A_{p}(z)=X(z) A_{p}(z)-B_{q}(z)$

and in time domain this becomes

$$
e(n)=a_{k}(n) * x(n)-b_{k}(n)
$$

Since $b_{k}(n)=0$ for $n>q$ then,

$$
e(n)=\left\{\begin{array}{rr}
x(n)+\sum_{l=1}^{p} a_{k}(l) x(n-l)-b_{k}(n) & n=1,2, \ldots, q \\
x(n)+\sum_{l=1}^{p} a_{k}(l) x(n-l) & n=n>q
\end{array}\right.
$$

The objective is to minimize the error, Equation (6) given as

$$
\begin{aligned}
& \varepsilon_{p, q}=\sum_{n=0}^{\infty}|e(n)|^{2} \\
& \varepsilon_{p, q}=\sum_{n=q+1}^{\infty}|e(n)|^{2}=\sum_{n=q+1}^{\infty}\left|x(n)+\sum_{l=1}^{p} a_{k} x(n-l)\right|^{2}
\end{aligned}
$$

Setting the partial derivates of $\varepsilon_{p, q}$ with respect to $a_{k}^{*}$ equal to zero, then, 
$\frac{\delta \varepsilon_{p, q}}{\delta a^{*}}=\sum_{n=q+1}^{\infty} \frac{\delta\left[e(n) e^{*}(n)\right]}{\delta a_{k}^{*}}=\sum_{n=q+1}^{\infty} e(n) \frac{\delta e^{*}(n)}{\delta a_{k}^{*}}=0 ; k=1,2, \ldots, p$

$\frac{\delta \varepsilon_{p, q}}{\delta a^{*}}=\sum_{n=q+1}^{\infty} e(n) x^{*}(n-k)=0 \quad k=1, \ldots, p$

Substituting (6) into (8), leads to

$$
\sum_{n=q+1}^{\infty}\left\{x(n)+\sum_{l=1}^{p} a_{k} x(n-l)\right\} x^{*}(n-k)=0
$$

or equivalently,

$$
\sum_{l}^{\infty} a_{k}\left[\sum_{n=q+1}^{\infty} x(n-l) x^{*}(n-k)\right]=-\sum_{n=q+1}^{\infty}\left[x(n) x^{*}(n-k)\right]
$$

which becomes

$$
\sum_{l=1}^{p} a_{k} r_{x x}(k, l)=-r_{x x}(k, 0) \quad k=1,2 \ldots, p
$$

where

$$
r_{x x}(k, l)=\sum_{n=q+1}^{\infty}\left(x(n-l) x^{*}(n-k)\right)
$$

\section{RESULT AND DISCUSSION}

\subsection{Consumer Load Consumption Pattern}

The average load for a typical week using daily data of 288 data points for one week is discussed. The average load consumption per day, at 5 minutes interval, is based on a typical weekday, public holiday and weekend loads consumption patterns. The public holiday loads and the weekend load pattern are similar, since these represent situations where the consumer is expected to be at home. Thus, the loads are categorized into two classes viz: the weekdays and weekends load, respectively. The load consumption for the weekdays: Monday to Friday is shown in Figure 2 to Figure 6 while the load for the weekend; Sunday and Saturday is illustrated in Figure 7 and Figure 8.

Generally, the pattern of the weekday load consumption implies that the consumer load demands during the early morning and late evening are high. For instance, Figure 2 shows higher load consumption values between 6 hour and 7 hour with peak at $0.2336 \mathrm{kWh}$. Furthermore, peak value of $0.2529 \mathrm{kWh}$ was obtained between 20 hour and 21 hour. Similarly, Figure 3 shows higher load consumption values between 5 hour and 6 hour; 20 hour and 21 hour; with peaks $0.2159 \mathrm{kWh}$ and $0.2732 \mathrm{kWh}$ respectively. Higher load on Wednesday 13th occurred between 6 hour and 8 hour with peak $0.2200 \mathrm{kWh}$ while $0.2754 \mathrm{kWh}$ was the peak load observed between 19 hour 30 minutes and 22 hour in the evening as shown in Figure 4.

In addition, peak load recorded between 6 hour and 8 hour as well as between 19 hour and 21 hour 40 minutes on Thursday, 14th are $0.2878 \mathrm{kWh}$ and $0.2503 \mathrm{kWh}$ respectively as shown in Figure 5. While that of Friday, 15th occurred between 6 hour and 7 hour at $0.2434 \mathrm{kWh}$; and between 19 hour and 22 hour stands at $0.2502 \mathrm{kWh}$ as illustrated by Figure 6 . The high load demands at these peak periods of the day occurred due to the early morning and late evening preparations which include cooking of food, switching ON of appliances such as television, computers and iron.
However, load consumption between 8 hour and 19 hour was relatively low and stable below $0.017 \mathrm{kWh}$ for all weekdays reported. This can be attributed to the absence of the consumer within this period, moreover, most appliances are switched OFF except the refrigerator. The weekday load consumption between 1 hour and 5 hour; 21 hour and 24 hour, fluctuated between $0.1 \mathrm{kWh}$ and $0.017 \mathrm{kWh}$ respectively. The fluctuation is as a result of 'ON' and 'OFF' cycle of the air conditioner and the refrigerator from late night till the early morning.

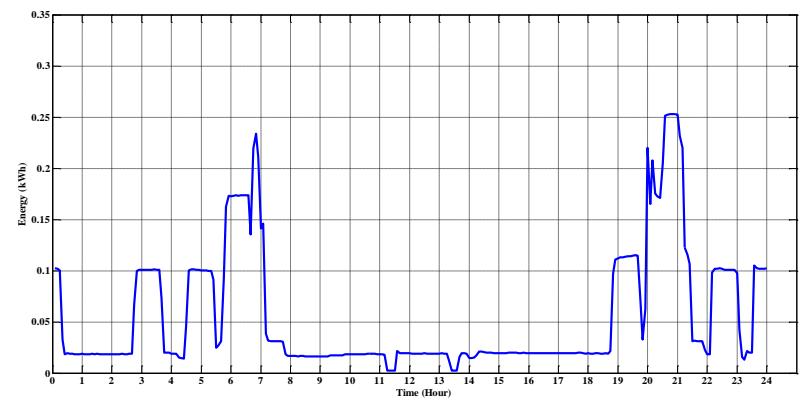

Figure 2. Consumer Load Consumption on Monday

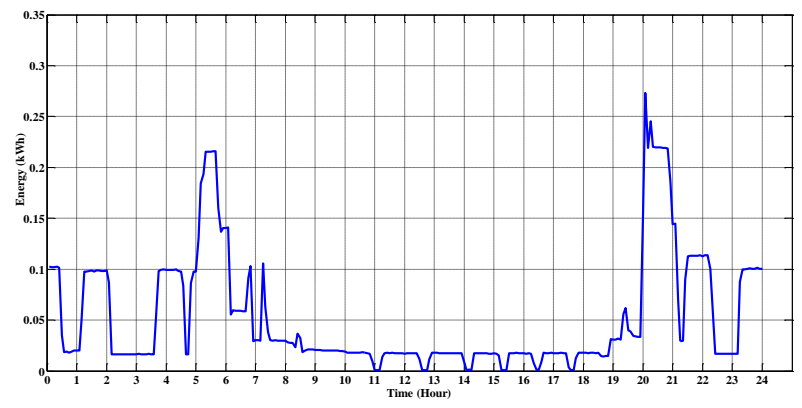

Figure 3. Consumer Load Consumption on Tuesday

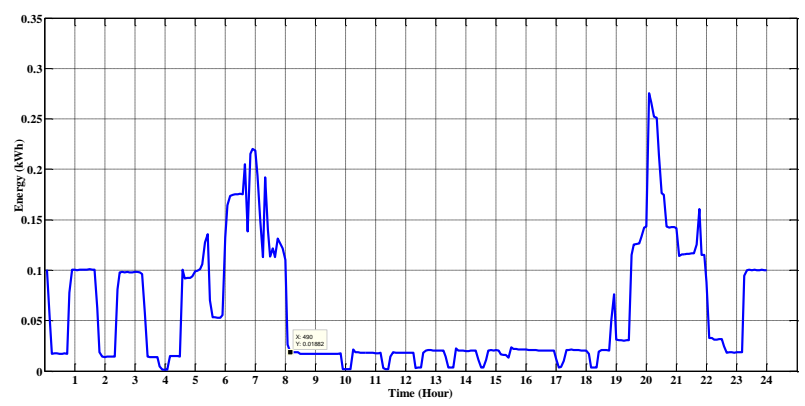

Figure 4. Consumer Load Consumption on Wednesday

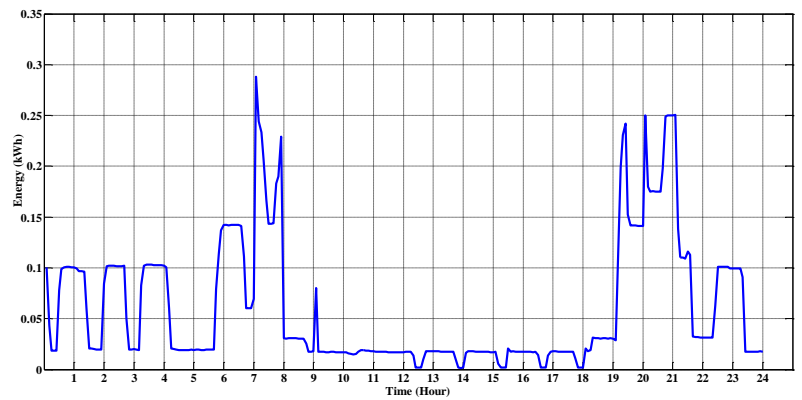

Figure 5. Consumer Load Consumption on Thursday 


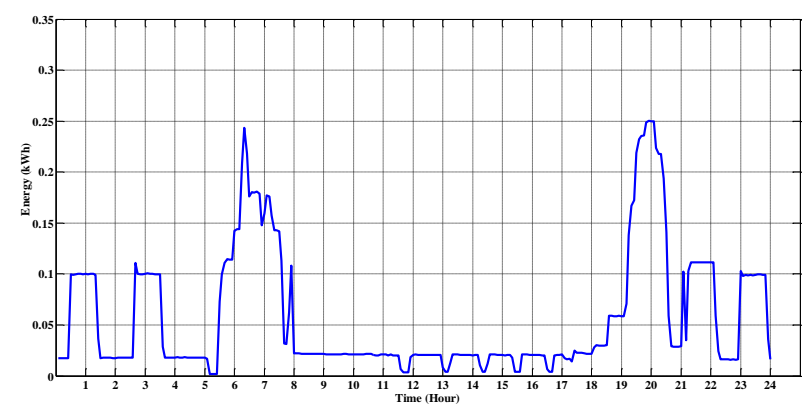

Figure 6.Consumer Load Consumption on Friday

Furthermore, Figure 7 and Figure 8 illustrate the weekend load consumption for Sunday and Saturday respectively. Unlike the weekday loads, where higher values occurred between the 6 hour to 8 hour in the morning and the 19 hour to 22 hour in the evening. The load consumption during weekend is higher between the 8 hour 20 minutes and 9 hour 55 minutes. This trend is also observed at 20 hour 10 minute and 21 hour 55 minute for Sunday while that of Saturday is between the 8 hour 10 minute and 10 hour in the morning and between 19 hour 55 minute and 22 hour 40 minute in the evening. The load consumptions for weekends are lower within these periods when compared with the load consumption on weekdays. This is probably due to the fact that the consumer is not in anticipation of going to work early and moreover, early morning preparation are delayed to convenient time during the day.

In addition, load consumption between the 8 hour and 19 hour that was stable below $0.017 \mathrm{kWh}$ for weekdays differs from the weekends load consumption within the same period. Whereas the weekdays load consumption is lower and relatively constant, the weekends load fluctuates between $0.01458 \mathrm{kWh}$ and $0.2976 \mathrm{kWh}$ within these periods. The peak of $0.2976 \mathrm{kWh}$ and $0.1629 \mathrm{kWh}$ between 8 hour 20 minutes and 9 hour 55 minutes; and between 15 hour and 16 hours was recorded respectively on Sunday as shown in Figure 7. On the other hand, $0.2353 \mathrm{kWh}$ peak value occurred between 8 hour and 10 hour, while peak value of $0.2113 \mathrm{kWh}$ between 15 hour and 16 hour was recorded for Saturday as shown in Figure 8. These times correspond to the cooking periods which require more load demands. Furthermore, late nig]ht and early morning consumptions are similar to weekdays in terms of pattern and load consumption.

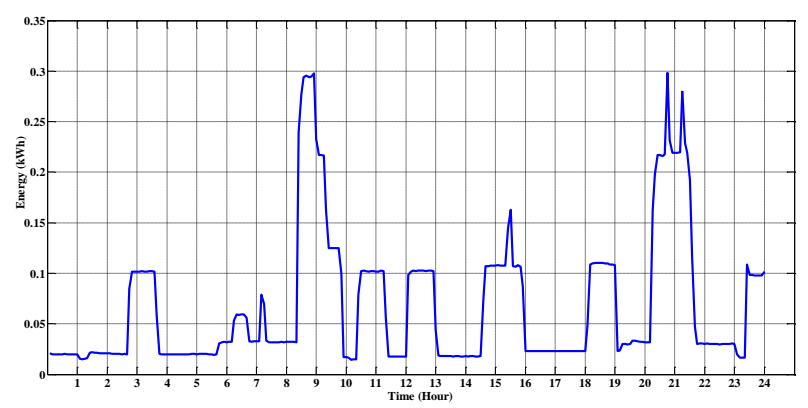

Figure 7. Consumer Load Consumption on Sunday

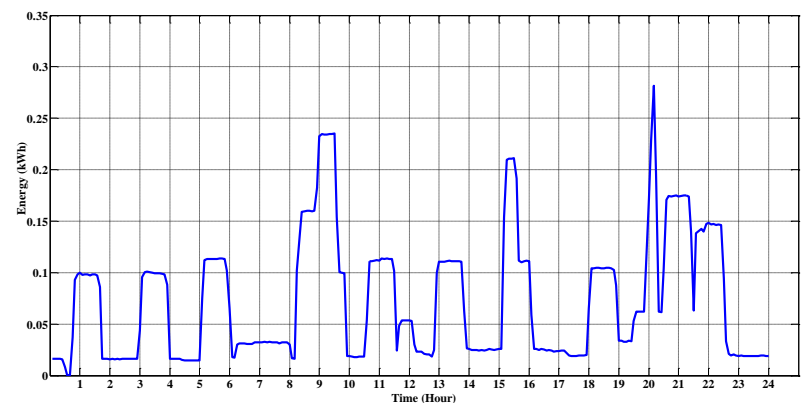

Figure 8. Consumer Load Consumption on Saturday

\subsection{Appropriate Model Order Selection of for Consumer Load}

Having acquired the daily consumer data consumption and plotted as indicated in Figure 1 to Figure 8, the prediction of the load consumption was then carried out in order to monitor the consumer activities which could be used to prevent the stealing of electricity. AR model was used to predict the consumer load using the acquired data and the results has been presented [18]. However, the selection of appropriate model order which is essential to using AR model as a predictor is difficult and led to higher model order selection. Nevertheless, to select ARMA model parameters for load prediction, the parameters estimated for AR model in [18] was used as a basis for obtaining the correct model order for ARMA model. Once the AR model order is obtained, the MA is estimated by fine tuning the model order using trial and error approach. In the process, different model orders such as ARMA $(10,8)$, ARMA (8, $6)$ and $\operatorname{ARMA}(6,4)$ were investigated after appropriate fine tuning. Furthermore, the mean square error of these models was carried out to see which order is preferred. Naturally, it is impossible to obtain zero error in the predicted values however, a good predictor would require minimum model order and accurate coefficients in order to obtain very small error. The result of the MSE for a typical week is illustrated in Table 1.

Generally, the MSE for ARMA $(8,6)$ and $\operatorname{ARMA}(6,4)$ are lower than ARMA $(10,8)$ meaning they are better for consumer load prediction. In addition, the MSE of ARMA $(8,6)$ is observed to be lower in some days such as day 13 and day 16 when compared to ARMA $(6,4)$. However, since the MSE of both $\operatorname{ARMA}(8,6)$ and $\operatorname{ARMA}(6,4)$ are very close and to prevent overrepresentation of data due to parsimony, ARMA $(6,4)$ with the lower model order was preferred and used in this study for the consumer load prediction. The consumer load prediction results for a typical weekday and weekend for ARMA $(10,8)$ and $\operatorname{ARMA}(8,6)$ are shown in Figure $9(\mathrm{a}-\mathrm{b})$ and Figure 10 (ab) while a one-week prediction based on $\operatorname{ARMA}(6,4)$ are illustrated in Figure 11(a-g) respectively. 
Table 1. Mean Square Error for ARMA Model Prediction.

\begin{tabular}{|c|c|c|c|}
\hline & $\begin{array}{c}\text { Mean } \\
\text { Square Error }\end{array}$ & $\begin{array}{l}\text { Maximum } \\
\text { Error }\end{array}$ & $\begin{array}{l}\text { Minimum } \\
\text { Error }\end{array}$ \\
\hline \multicolumn{4}{|l|}{ Sunday } \\
\hline $\begin{array}{l}\text { ARMA } \\
(10,8)\end{array}$ & 0.0000656 & 0.0285 & -0.0327 \\
\hline $\begin{array}{l}\text { ARMA } \\
(8,6)\end{array}$ & 0.0000611 & 0.0284 & -0.0362 \\
\hline $\begin{array}{l}\text { ARMA } \\
(6,4)\end{array}$ & 0.0000520 & 0.0261 & -0.0275 \\
\hline \multicolumn{4}{|l|}{ Monday } \\
\hline $\begin{array}{l}\text { ARMA } \\
(10,8)\end{array}$ & 0.0000544 & 0.0121 & -0.0275 \\
\hline $\begin{array}{l}\text { ARMA } \\
(8,6)\end{array}$ & 0.0000566 & 0.0131 & -0.0268 \\
\hline $\begin{array}{l}\text { ARMA } \\
(6,4)\end{array}$ & 0.0000484 & 0.0139 & -0.0233 \\
\hline \multicolumn{4}{|l|}{ Tuesday } \\
\hline $\begin{array}{l}\text { ARMA } \\
(10,8)\end{array}$ & 0.0000778 & 0.0205 & -0.0437 \\
\hline $\begin{array}{l}\text { ARMA } \\
(8,6)\end{array}$ & 0.0000745 & 0.0203 & -0.0435 \\
\hline $\begin{array}{l}\text { ARMA } \\
(6,4)\end{array}$ & 0.0001482 & 0.0173 & -0.0471 \\
\hline \multicolumn{4}{|l|}{ Wednesday } \\
\hline $\begin{array}{l}\text { ARMA } \\
(10,8)\end{array}$ & 0.0000270 & 0.0065 & -0.0222 \\
\hline $\begin{array}{l}\text { ARMA } \\
(8,6)\end{array}$ & 0.0000259 & 0.0052 & -0.0227 \\
\hline $\begin{array}{l}\text { ARMA } \\
(6,4)\end{array}$ & 0.0000278 & 0.0033 & -0.0230 \\
\hline \multicolumn{4}{|l|}{ Thursday } \\
\hline $\begin{array}{l}\text { ARMA } \\
(10,8)\end{array}$ & 0.0002116 & 0.0086 & -0.0492 \\
\hline $\begin{array}{l}\text { ARMA } \\
(8,6)\end{array}$ & 0.0001986 & 0.0035 & -0.0462 \\
\hline $\begin{array}{l}\text { ARMA } \\
(6,4)\end{array}$ & 0.0000954 & 0.0202 & -0.0447 \\
\hline \multicolumn{4}{|l|}{ Friday } \\
\hline $\begin{array}{l}\text { ARMA } \\
(10,8)\end{array}$ & 0.0001477 & 0.0055 & -0.0393 \\
\hline $\begin{array}{l}\text { ARMA } \\
(8,6)\end{array}$ & 0.0001340 & 0.0055 & -0.0384 \\
\hline $\begin{array}{l}\text { ARMA } \\
(6,4)\end{array}$ & 0.0000295 & 0.0056 & -0.0189 \\
\hline \multicolumn{4}{|l|}{ Saturday } \\
\hline $\begin{array}{l}\text { ARMA } \\
(10,8)\end{array}$ & 0.0001174 & 0.0315 & -0.0503 \\
\hline $\begin{array}{l}\text { ARMA } \\
(8,6)\end{array}$ & 0.0000720 & 0.0324 & -0.0480 \\
\hline $\begin{array}{l}\text { ARMA } \\
(6,4)\end{array}$ & 0.0000850 & 0.0323 & -0.0488 \\
\hline
\end{tabular}

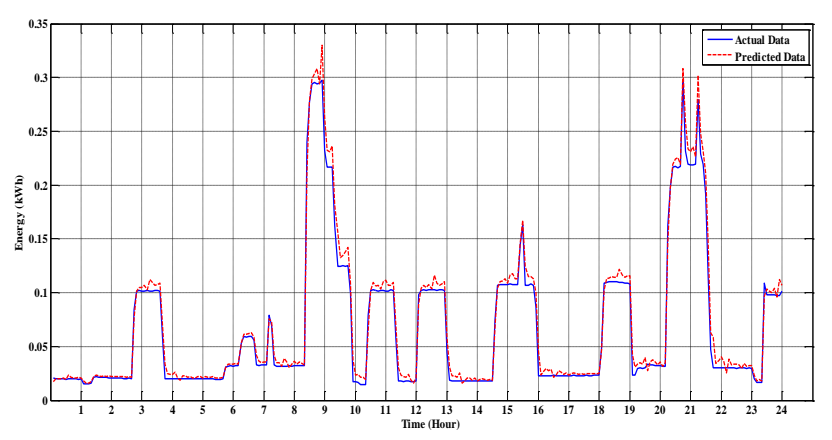

(a) ARMA $(10,8)$ Model Prediction for Sunday

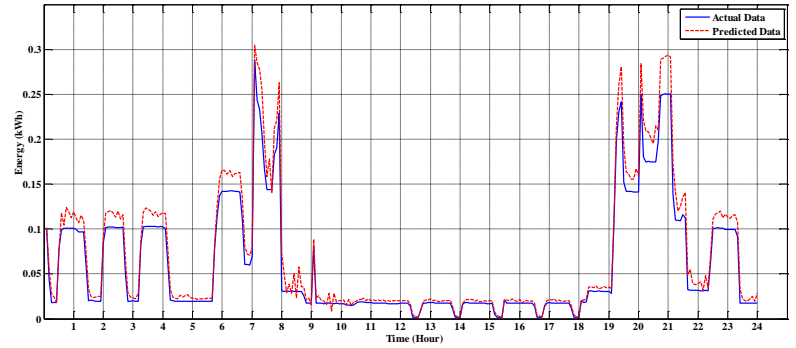

(b) ARMA $(10,8)$ Model Prediction based for Thursday Figure 9.

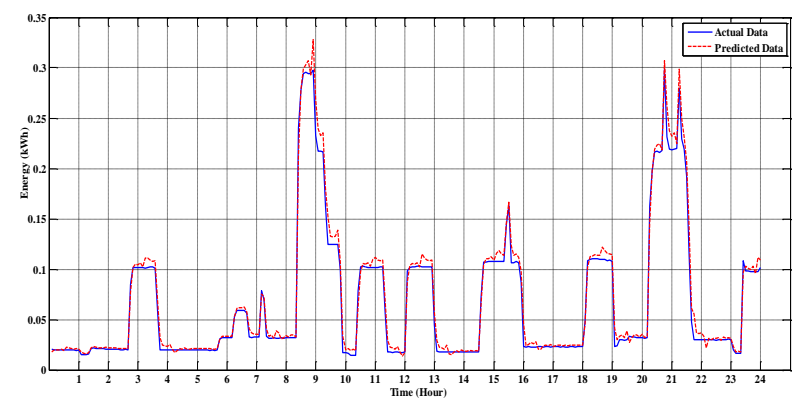

(a) ARMA $(8,6)$ Model Prediction for Sunday

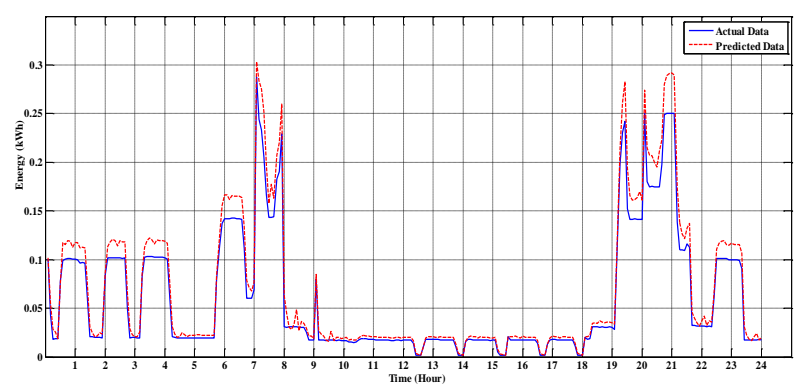

(b) ARMA $(8,6)$ Model Prediction for Thursday

Figure 10

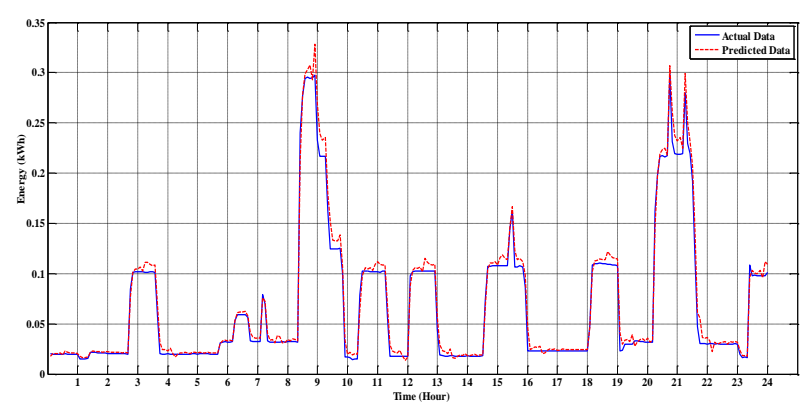

(a) ARMA $(6,4)$ Model Prediction for Sunday

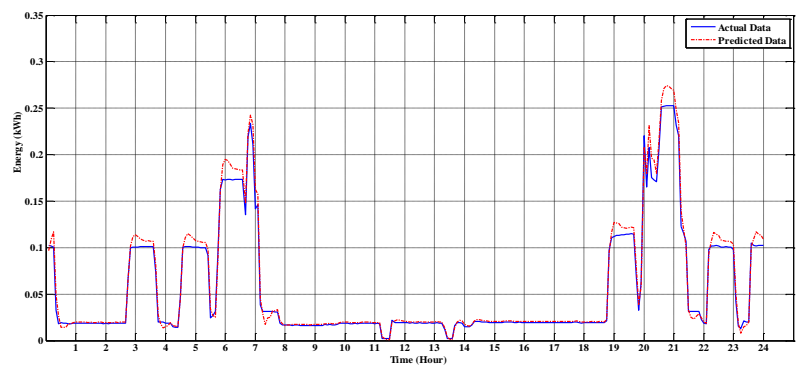

(b) ARMA $(6,4)$ Model Prediction for Monday 


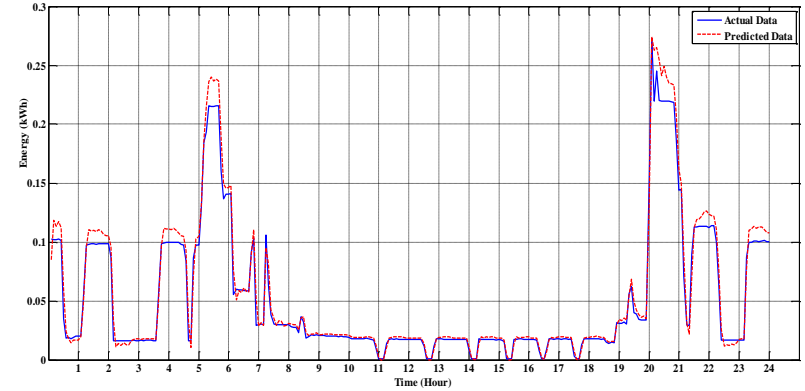

(c) ARMA $(6,4)$ Model Prediction for Tuesday

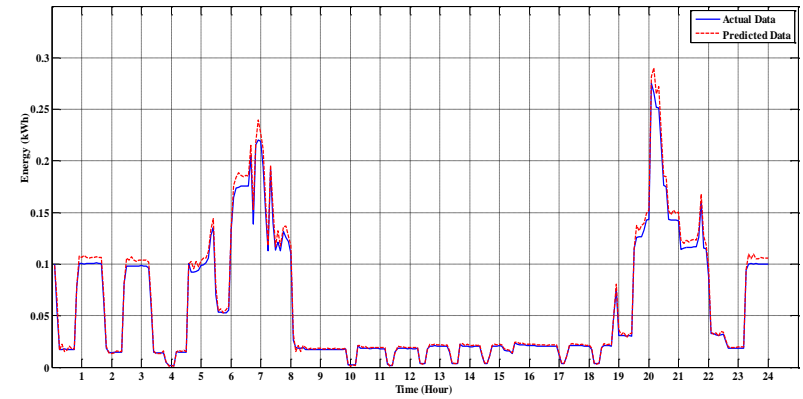

(d) ARMA $(6,4)$ Model Prediction for Wednesday

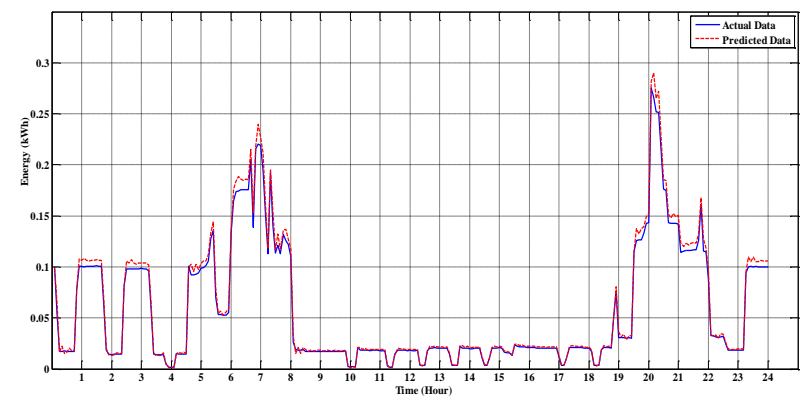

(e) ARMA $(6,4)$ Model Prediction for Thursday

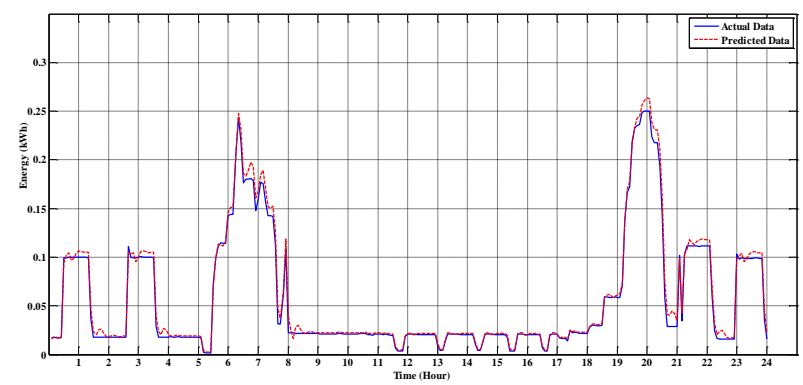

(f) $\operatorname{ARMA}(6,4)$ Model Prediction for Friday

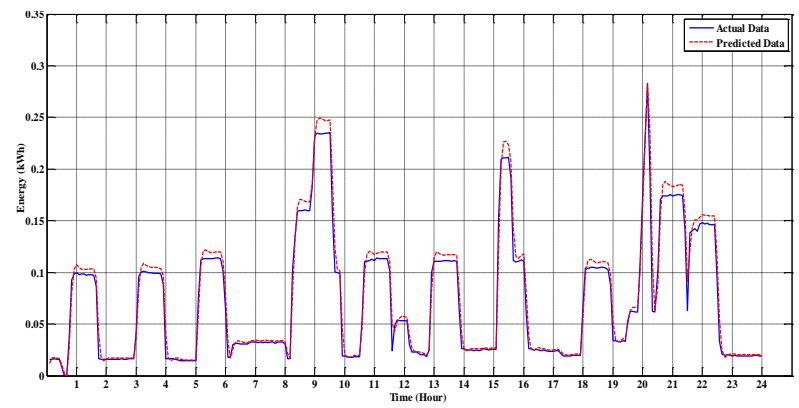

(g) ARMA $(6,4)$ Model Prediction for Saturday

Figure 11. ARMA $(6,4)$ Model Prediction for a Week
As expected, the ARMA $(6,4)$ followed the consumer load both at the peak and the valley. One of the advantages of the ARMA $(6,4)$ model is that the model order as well as the model coefficients required to predict the consumer load are smaller when compared with ARMA $(10,8)$ and ARMA $(8,6)$. Since it is expected to be implemented on line, the computational time and the volume of data will be minimal.

\subsection{Comparison between ARMA Model Orders}

Figure 12 and Figure 13 depict the compared results obtained when a typical weekend and weekday data of consumer load were predicted based on ARMA $(10,8)$, ARMA (8, 6), ARMA $(6,4)$ and the actual data. Furthermore, Figure 14 (a-c) and Figure 15 (a-b) show the zoomed version of different hours of Figure12 and 13 respectively, for clarity. Though the three ARMA models were able to predict the power consumed, however, ARMA $(6,4)$ was able to follow the load pattern better than other models as illustrated in Figure 14 (a-c) for weekend and Figure 15 (a-b).

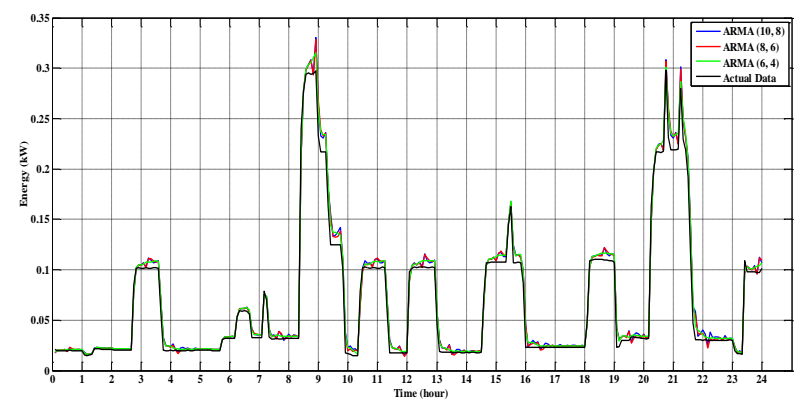

Figure 12. Comparison of weekend consumer load prediction based on $\operatorname{ARMA}(10,8), \operatorname{ARMA}(8,6)$ and ARMA $(6,4)$.

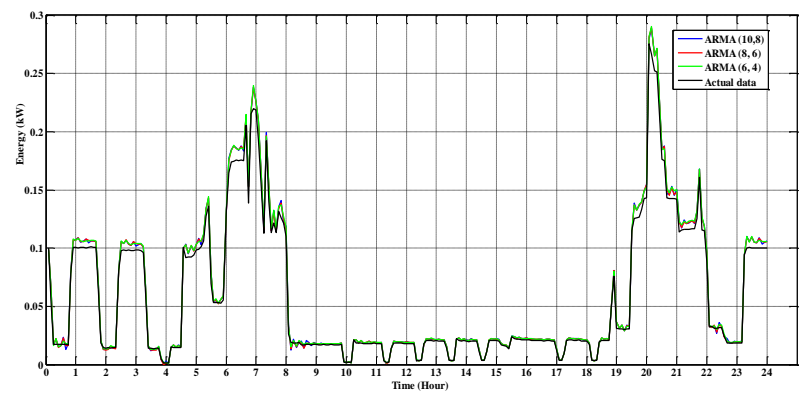

Figure 13. Comparison of weekday consumer load prediction based on $\operatorname{ARMA}(10,8), \operatorname{ARMA}(8,6)$ and ARMA $(6,4)$. 


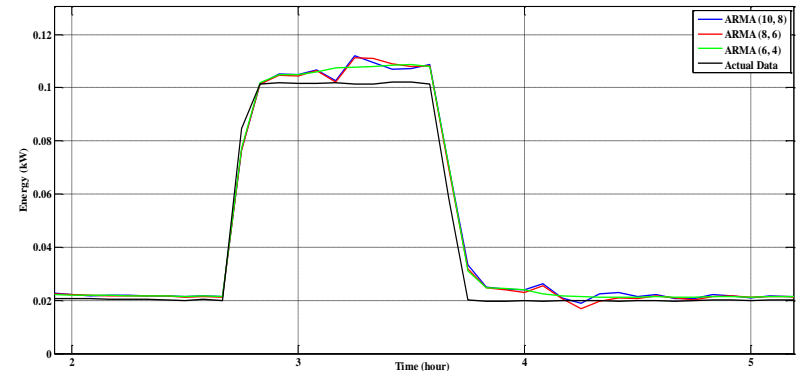

(a) Zoom version of 2 hour and 5 hour

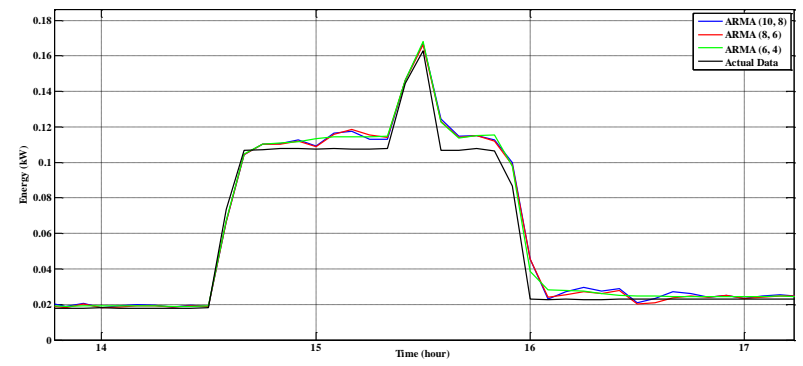

(b) Zoom version of 14 hour and 17 hour

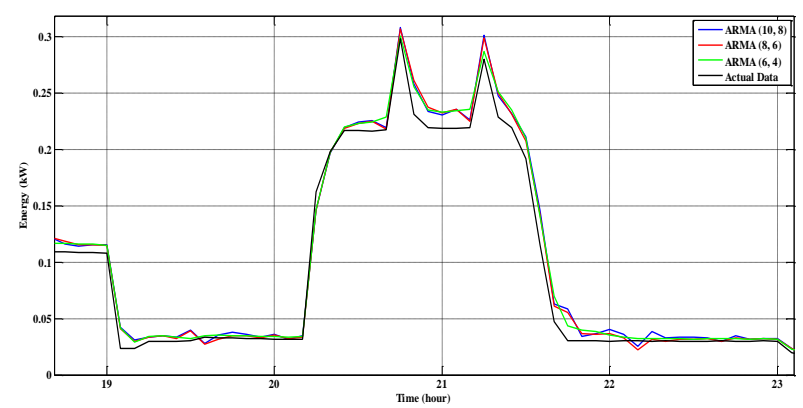

(c) Zoom version between 19 hour and 23 hour Figure 14.

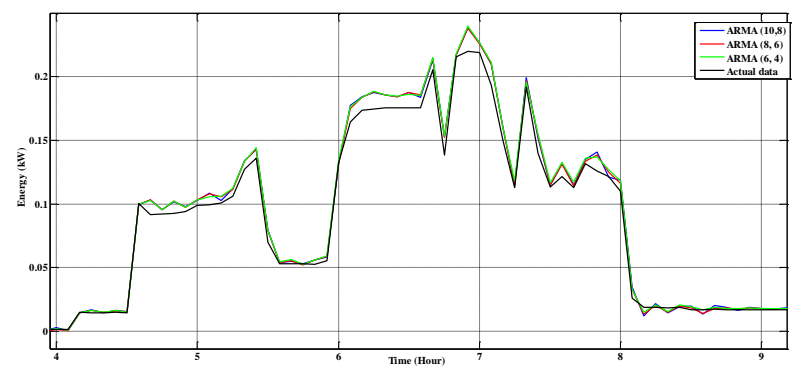

(a) Weekday zoom version between 4 hour and 9 hour

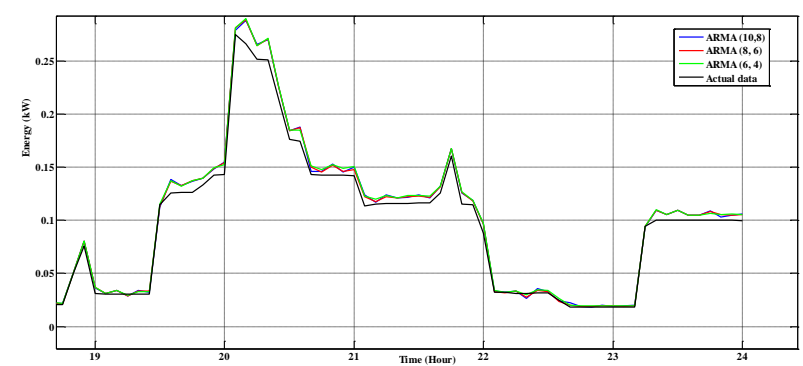

(b) Weekday Zoom version of 19 hour and 24 hour Figure 15. Comparison between ARMA $(6,4)$ and AR (20) Models load predictions.

\subsection{Comparison between AR (20) and ARMA (6, 4)} Models Prediction.

The load prediction using AR (20) and ARMA (6 4) for a typical weekday and weekend is illustrated in Figure 16 (ab) and Figure 17 respectively. Though the AR model is able to predict the power consumed, however, the ARMA $(6,4)$ was able to predict both the peaks and the valley as show between interval 0 and 500th minute as well as between 1125 minute and 1440 minute.

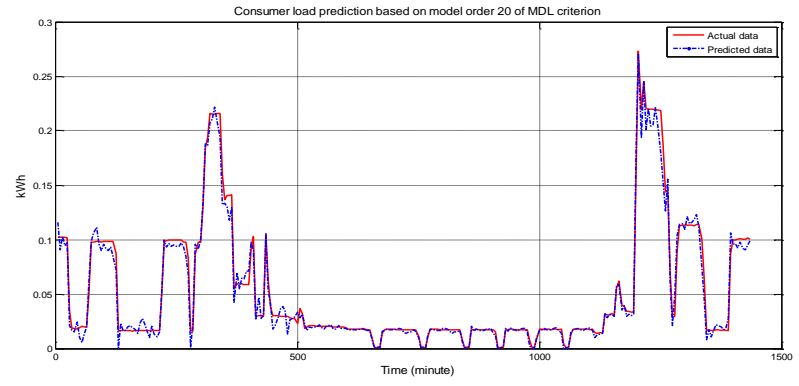

(a) AR (20) Model

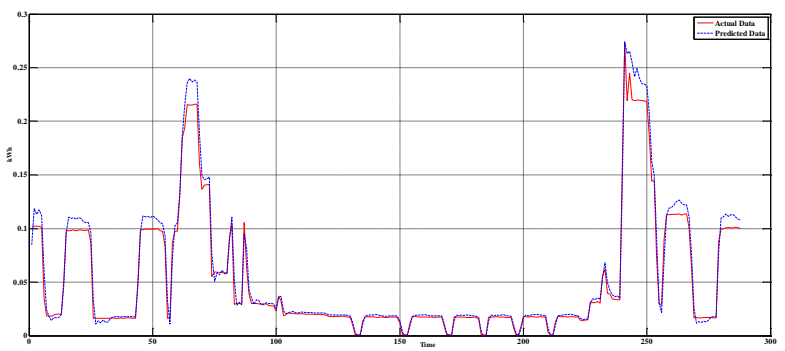

(b) ARMA $(6,4)$ Model

Figure 16. Weekday Model Comparison

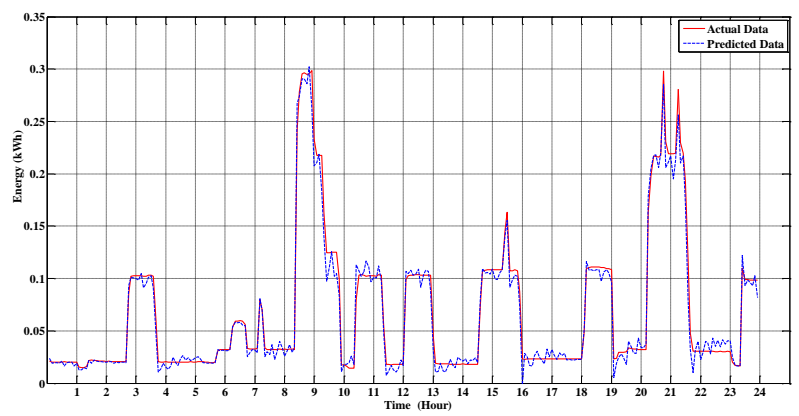

(a) AR (20) Model

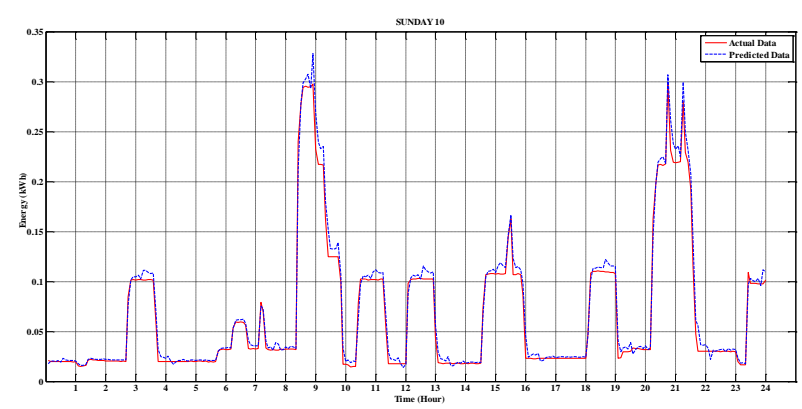

(b) ARMA $(6,4)$ Model

Figure 17. Weekend Model Comparison 


\section{CONCLUSION}

ARMA $(6,4)$ model has been used to predict consumer load in this study. This facilitates the monitoring of individual consumer activities connected on power distribution network. Average energy consumption data acquired from consumer load prototype within 24 hours and having 288 data points was modeled. Consequently, 5minute step ahead load prediction was achieved. Furthermore, comparison between three different ARMA models; ARMA $(10,8)$, ARMA $(8,6)$ and ARMA $(6,4)$ show that ARMA $(6,4)$ prediction is preferable in that it was able to follow the load pattern better than other models. In addition, ARMA $(6,4)$ model as a predictor is accurate when compared with AR (20) used in our earlier work. It has lower model coefficients on one hand and predict the valley and peaks consistently than AR model.

\section{REFERENCES}

[1] S. S. Pappas et al., "Electricity demand load forecasting of the Hellenic power system using an ARMA model," Electr. Power Syst. Res., vol. 80, no. 3, pp. 256-264, 2010.

[2] C.-N. Yu, P. Mirowski, and T. K. Ho, "A sparse coding approach to household electricity demand forecasting in smart grids," IEEE Trans. Smart Grid, vol. 8, no. 2, pp. 738-748, 2017.

[3] Y. Liu, W. Wang, and N. Ghadimi, "Electricity load forecasting by an improved forecast engine for building level consumers," Energy, vol. 139, pp. 1830, 2017.

[4] N. Amjady and F. Keynia, "A new neural network approach to short term load forecasting of electrical power systems," Energies, vol. 4, no. 3, pp. 488-503, 2011.

[5] P. C. Chang, C. Y. Fan, and J. J. Lin, "Monthly electricity demand forecasting based on a weighted evolving fuzzy neural network approach," Int. J. Electr. Power Energy Syst., vol. 33, no. 1, pp. 17-27, 2011.

[6] E. Diaconescu, "The use of NARX neural networks to predict chaotic time series," WSEAS Trans. Comput. Res., vol. 3, no. 3, pp. 182-191, 2008.

[7] H. K. Alfares and M. Nazeeruddin, "Electric load forecasting: Literature survey and classification of methods," Int. J. Syst. Sci., 2002.

[8] N. Cristianini and J. Shawe-Taylor, An introduction to support vector machines and other kernel-based learning methods. Cambridge university press, 2000.

[9] R. P. Singh, P. X. Gao, and D. J. Lizotte, "On hourly home peak load prediction," in Third International Conference on Smart Grid Communications , 2012, pp. $163-168$.

[10] I. Koprinska, M. Rana, and V. Agelidis, "Electricity Load Forecasting: A Weekday-Based Approach," in Artificial Neural Networks and Machine Learning ICANN 2012, vol. 7553, A. Villa, W. Duch, P. Érdi, F. Masulli, and G. Palm, Eds. Springer Berlin Heidelberg, 2012, pp. 33-41.

[11] D. J. Trudnowski, S. Member, W. L. Mcreynolds, J. M. Johnson, and A. Member, "Real-Time Very Short-Term Load Prediction for Power-System Automatic Generation Control," vol. 9, no. 2, pp. 254-260, 2001.

[12] C. O. Adika and L. Wang, "Short term energy consumption prediction using bio-inspired fuzzy systems," in North American Power Symposium (NAPS), 2012, pp. 1-6.

[13] W. Yan, "Toward automatic time-series forecasting using neural networks," IEEE Trans. Neural Networks Learn. Syst., vol. 23, no. 7, pp. 1028-1039, 2012.

[14] N. I. Sapankevych and R. Sankar, "Time series prediction using support vector machines: a survey," IEEE Comput. Intell. Mag., vol. 4, no. 2, pp. 24-38, 2009.

[15] C. Guan, P. B. Luh, L. D. Michel, Y. Wang, and P. B. Friedland, "Very Short-Term Load Forecasting: Wavelet Neural Networks With Data Pre-Filtering," Power Syst. IEEE Trans., vol. 28, no. 1, pp. 30-41, 2013.

[16] H. Y. Yang, H. Ye, G. Wang, J. Khan, and T. Hu, "Fuzzy neural very-short-term load forecasting based on chaotic dynamics reconstruction," Chaos, Solitons \& Fractals, vol. 29, no. 2, pp. 462-469, 2006.

[17] C. Y. Fok and M. I. Vai, "Very Short Term Load Forecasting for Macau Power System," in Intelligent Computing Technology, H. De-Shuang, J. Changjun, B. Vitoantonio, and C. F. Juan, Eds. Berlin Heidelberg: Springer, 2012, pp. 538-546.

[18] A. I. Abdullateef, M.-J. E. Salami, and M. F. Akorede, "Intelligent technique for electricity theft identification using autoregressive model," LAUTECH J. Eng. Technol., vol. 12, no. 1, pp. 1-12, 2018.

[19] A. I. Abdullateef, M. J. E. Salami, M. A. Musse, M. A. Onasanya, and M. I. Alebiosu, "New consumer load prototype for electricity theft monitoring," IOP Conf. Ser. Mater. Sci. Eng., vol. 53, no. 1, p. 12061, 2013.

[20] B. Friedlander, "A recursive maximum likelihood algorithm for ARMA spectral estimation," Inf. Theory, IEEE Trans., vol. 28, no. 4, pp. 639-646, 1982. 